\title{
Educational Method for Developing Assessment Skills of Nursing Students
}

\author{
Keiko Aizu ${ }^{*}$, Kasumi Mikami1, Ryoko Tsuchiya ${ }^{2}$, Mayumi Shimizuㄹ, \\ Naoki Oka ${ }^{4}$, Yoshiko Nishizawa ${ }^{1}$ \\ ${ }^{1}$ Graduate School of Health Sciences, Hirosaki University, Aomori, Japan \\ ${ }^{2}$ School of Medicine \& Hospital, Hirosaki University, Aomori, Japan \\ ${ }^{3}$ Institute of Radiation Emergency Medicine, Hirosaki University, Aomori, Japan \\ ${ }^{4}$ Faculty of Human Life Sciences, Tokushima Bunri University, Tokushima, Japan \\ Email: *aizu@hirosaki-u.ac.jp
}

How to cite this paper: Aizu, K., Mikami, K., Tsuchiya, R., Shimizu, M., Oka, N. and Nishizawa, Y. (2018) Educational Method for Developing Assessment Skills of Nursing Students. Open Journal of Nursing, 8, 518-530.

https://doi.org/10.4236/ojn.2018.88039

Received: July 26, 2018

Accepted: August 20, 2018

Published: August 23, 2018

Copyright (c) 2018 by authors and Scientific Research Publishing Inc. This work is licensed under the Creative Commons Attribution International License (CC BY 4.0).

http://creativecommons.org/licenses/by/4.0/

(c) (i) Open Access

\begin{abstract}
This study aimed to verify the effects of a new instructional method to structure knowledge. The research hypothesis was that "Structured knowledge improves assessment skills of students". Fifty-five second-year undergraduate students volunteered to participate in this study. They were randomized into either a group that received instructional intervention $(n=19$; intervention) or a group that did not $(\mathrm{n}=36$; non-intervention). A survey and instructional intervention comprised pre-tests, individual instructional intervention, participant self-studies and post-tests. The students attempted one pre- and one post-test task, each comprising concept map drawing and assessment of actual patients with diabetes. Participants who received educational intervention described concept maps regarding the pathophysiology and nursing of diseases, and we taught a learning strategy to understand relationships between concepts and the assumption of clinical assessment. The results of the concept map drawing task showed that post-test structural knowledge scores were significantly higher for the intervention, than the non-intervention group $(p<0.001)$. Post-test scores of the intervention group for assessment skills regarding "nursing problems and factors" were significantly better than pre-test scores $(p<0.001)$, and significantly higher than those for the non-intervention group $(p<0.01)$. The educational intervention in this study seemed to augment the ability to identify nursing problems, although we did not teach assessment strategies. The intervention seemed to confer structured knowledge with explicit conditions for applicability. Structured knowledge with explicit conditions and learning how to use knowledge to assess patients before a clinical practicum seemed to augment assessment skills.
\end{abstract}




\section{Keywords}

Concept Map, Structural Knowledge, Cognitive Psychology, Learning

\section{Introduction}

Nurses are now required to have well-developed assessment skills due to changes in the structure of illnesses among aged patients and advancements in medical technology. The "nursing process" is the thinking pathways that a nurse follows when taking care of patients and they include "assessment", "nursing diagnosis", "planning", "implementation", and "evaluation" [1]. "Assessment" is the process of collecting information about patients, analyzing the situation, and understanding the nature of problems or potential problems [2]. Good assessment skills are critical because "nursing diagnosis" "planning" and "implementation" are based on the initial "assessment". Nursing students must care for patients in the same manner as licensed nurses even though they are participating in clinical practicums. Thus, nursing students should have good assessment skills.

However, a statement issued by the Ministry of Health, Labour and Welfare in Japan [3] has highlighted the possibility that students might not learn how to apply acquired knowledge to assessment. This might be because they are unable to think and actively learn because much knowledge needs to be learned within a limited amount of time, and curricula have become overloaded [3].

Nursing students in the early stage of a clinical practicum evaluate the health status of a patient and judge which problems need intervention by applying knowledge. Thereafter, students become enabled to effectively apply the nursing process.

\section{Background and Literature Review}

\subsection{Instructional Tools for Assessment in Nursing Education}

Optimal utilization of knowledge enables students to effectively assess patients. Therefore, recognizing the relationship between student knowledge and assessment skills is important when discussing instructional tools that augment assessment skills. However, studies of assessment skills in relation to knowledge are scant despite abundant research on assessment education. Standardized patients or the Objective Structured Clinical Examination are used for assessment education in the USA and Japan [4] [5]. These instructional tools focus on student behavior and ways of thinking. Whether a sufficient number of studies have investigated knowledge used for assessment is difficult to demonstrate.

Yula, H. and Walsh, M.B. [6] state that using the nursing process will facilitate the application of vast amounts of knowledge to clinical situations in an organized form.

When students learn about the logical thinking of the nursing process, they should apparently have a wide knowledge of nursing, and acquire a method to 
apply such knowledge.

Many cognitive psychology research findings related to problem-solving processes have been reported. Working memory is effective in assessment education [7]. In addition, the Learning Theory underlies the notion that how nursing students learn affects the Conceptual Frame [8]. Therefore, we focused on cognitive psychology to devise an educational learning method associated with assessment.

\subsection{Working Memory Based on Cognitive Psychology}

Cognitive psychologies recognize that a concept held by a person can be represented as a node in a network with the properties of the concept represented as labeled relational links from that node to other concept nodes [9]. When one concept is activated in a problem-solving situation, activation spreads to other nodes linked in the network and this promotes the use of knowledge for problem-solving. Chi, M.T., Feltovich, P.J. and Glaser, R. compared networks of concepts and the knowledge of physics experts and novices [10]. They viewed the network of the experts as representing internal schemata, with category names as access labels for the appropriate schemata. The schemata of the experts contained a great deal of procedural knowledge, with explicit conditions for applicability. Novice schemata can be characterized as containing sufficient declarative knowledge but lacking abstract solution methods [10].

\subsection{Working Memory Model and Acquisition of Knowledge}

The representation of knowledge not only improves the applicability of knowledge to problem-solving but also relates to the process of acquiring new knowledge [11]. Baddeley, A.D. viewed the process of acquiring new knowledge as a working memory model and proposed the cognitive processing system, "working memory" that facilitates the retention of new concepts in long-term memory [12]. Cognitive processing in working memory is assumed to be associations of new and extant concepts or knowledge in long-term memory, while referring to long-term memory when a new concept is introduced [11]. The structure and application of knowledge are supposedly augmented by conscious memorization, namely, the storage of new information while remaining conscious of the scene in which the information will be applied. In terms of nursing, the following can be considered. Learning new knowledge while remaining conscious of how to apply it to assessments in a clinical scene augments knowledge structure and application in the clinical scene.

\subsection{Instructional Method for Structural Knowledge}

Ichikawa, S. suggested "cognitive counseling" as a practical technique for linking cognitive theory and education [13]. A cognitive counselor is an individual learning consultant who handles problems and/or concerns with learning and instructs individuals in learning strategies with which to solve their own prob- 
lems. Cognitive counseling comprises diagnostic guidance to identify learning-associated problems and gives instruction that includes graphical and figurative explanations, virtual teaching and instructive induction. The suggested merit of using a graphic is that it can clearly convey a concept and the structure of the content to be handled. Cognitive counseling focuses on "supporting independence" so that individuals can acquire skills to actively learn.

From the above, we considered acquiring medical knowledge in association with a clinical scene and graphically augmented structural knowledge with explicit conditions for applicability. Therefore, we attempted to teach a learning strategy using "concept maps". Furthermore, intervention was aimed at teaching students to understand learning strategies and actively apply them.

\section{Purposes}

This study aimed to verify the effect of a new instructional method with which to structure knowledge. The research hypothesis was that "Structured knowledge improves assessment skills of students". The following issues were discussed: Implementation of instructional intervention so that students could understand the learning method required to acquire knowledge in relation to clinical scenes, verification of the effects of intervention on structured knowledge and of the effects of structured knowledge on assessment skills based on a relationship between the two after intervention.

\section{Methods}

We assessed the effects of an intervention using before-and-after analysis.

\subsection{Experimental Procedure}

The survey and instructional intervention consisted of pre-tests, individual instructional interventions, self-study by participants, and post-tests. The study proceeded between February and April 2015.

\subsection{Participants}

The purpose and ethical considerations of the present study were described to 78 second-year undergraduate nursing students. Among them, 55 provided written, informed consent to participate voluntarily in this study, which started before a clinical practicum that included a clinical assessment.

\subsection{Pre-Test}

Participants performed two tasks based on information derived from actual diabetic patients because they had already learned about diabetes in their student curriculum. Furthermore, many opportunities for a clinical scene are likely to arise because of the high prevalence of diabetes.

\subsubsection{Concept Map Drawing Task}

The students drew relationships between concepts such as the pathophysiology, 
causes, symptoms, complications, diagnosis, treatment, nursing considerations and influences on lifestyle associated with diabetes, and created concept maps about diabetes within about 10 minutes.

\subsubsection{Assessment Task}

Written details about a patient with diabetes were presented to the students, who were then required to assess the ability of the patient to self-manage diet therapy. The details were based on an actual patient [14] and were considered by four researchers including nursing faculty members and clinical nurses. Table 1 summarizes the details of the patient.

\subsection{Grouping}

Nineteen and 36 participants were randomly assigned to receive instruction (intervention group) or not (non-intervention group).

\subsection{Student Self-Study}

The students were directed to study the pathophysiology, diagnosis, treatment, diet therapy and nursing considerations regarding diabetes. The assignment was for one A3 size handout, but participants could add content and pages as needed. The period of self-study was the two months of spring break to eliminate the influence of other lectures. The intervention group was directed to apply self-study after receiving instructional intervention, and the other group was directed to do self-study using their current learning method.

\subsection{Instructional Intervention}

The instructional intervention aimed to have participants learn the strategy to acquire knowledge associated with clinical scenes based on actual patients with lung cancer or liver cirrhosis. The intervention group created concept maps regarding the pathophysiology and nursing of diseases, and we taught a learning strategy to understand the relationships between concepts and the assumption of clinical assessment. Lung cancer and liver cirrhosis were selected because the symptoms are diverse and the status of the patient must be comprehensively captured based on knowledge. Nine and 10 students assessed patients with lung cancer and liver cirrhosis, respectively. Participants individually engaged in five 40 - to 90 -minute interventions. The procedure for educational intervention is described below.

\subsubsection{Intervention 1}

Instructors lectured the students about learning strategies based on cognitive theory using the working memory model. Students then studied lung cancer or liver cirrhosis by themselves for a period of 3 - 7 days.

\subsubsection{Interventions 2-4}

The students described concept maps regarding lung cancer or liver cirrhosis based on self-learned knowledge. We taught them to refer to a concept map 
Table 1. Summary of patient characteristics in assessment of ability to self-manage diet therapy.

Patient information: D.E., male; age, 54 years; Height, 173.7 cm; Weight 80.4 kg; Blood pressure 142/86 mmHg; Works for large supermarket.

History of present illness: Diagnosed with type 2 diabetes $\sim 20$ years ago.

Oral hypoglycemic agents from age 40 years; Insulin from 6 years ago.

Blood glucose not well controlled, due to alcohol consumption, etc. HbAlc 9.4\% (NGSP).

Reason for admission: Poor blood glucose control.

Outpatient assessment

Medication: Insulin injection before meals, before going to bed, self-check blood sugar before breakfast.

Diet therapy: Meals are supposed to be within $2000 \mathrm{kcal} /$ day.

Patient states that his wife manages his diet at home, and that he does not care too much.

Patient eats cafeteria lunch of meat and deep-fried foods.

Patient snacks on sweet bread before going home. Work ends late at night and usually eats supper

after $10 \mathrm{pm}$.

Average dietary intake: $\sim 2500 \mathrm{kcal} /$ day.

He smokes about 10 cigarettes and consumes $400-600 \mathrm{~mL}$ of alcohol daily.

Recent blood parameters: fasting blood glucose, $189 \mathrm{mg} / \mathrm{dL}$; HbAlc, $9.1 \%$.

Present medical status: Patient was hospitalized for about two weeks six years ago when insulin therapy was started. He stated that after discharge, he complied with diet therapy for about two months, but was busy with work and soon returned to his original lifestyle.

$\mathrm{He}$ is also aware that tobacco and alcohol are bad for diabetes, but he stated that to quit is worse as he needs them to work.

He talks about difficulties living with diet therapy and stated that he knows that therapy is good for his health, but he is unable to comply with everything that the doctor and nutritionist want him to do. This is because there are too many things involved.

model when associating knowledge. The model comprised the following indispensable items: 1) parts (functions) impaired by disease, 2) symptoms, 3) influences on daily life and distress experienced by the patient, 4) treatment and nursing, and 5) diagnosis and observation. Items 1 to 3 were linked in an orderly fashion, and items 4 and 5 were linked to items 1 to 4 as appropriate. During the second and third interventions, the students independently described concept maps to an instructor. For example, the instructor asked questions that guided the students to refer to the literature and derive a solution, depending on their level of understanding. The instructor asked few questions and taught little during the fourth intervention, allowing the students to describe concept maps by themselves and confirming their level of understanding. In addition, the instructor encouraged the students to draw the concept map model that they had described on a post-it note, so that they could check whether relevance was properly captured when they described something.

\subsubsection{Final Intervention}

The participants created concept maps and fulfilled assessment tasks associated with lung cancer and liver cirrhosis.

\subsection{Post-Test}

Participants created concept maps and assessed an actual diabetic patient. The 
amount of time spent in self-learning and the learning strategies applied were investigated using free description.

\subsection{Data Analysis}

\subsubsection{Structural Knowledge}

The numbers of links appropriately grasped and applied by the participants were calculated as indicators of structural knowledge based on what they described during the concept map drawing task.

\subsubsection{Assessment Skill}

Table 2 shows a checklist that we created to evaluate assessment skills. The validity of the checklist was determined by four investigators including two teachers and two clinical experts. The checklist included 37 items associated with "information gathering" and four associated with "nursing problems and factors". Scores for each category were calculated to determine levels of assessment skills of the students.

\subsubsection{Types of Applied Learning Strategies}

We classified learning strategies into understanding and non-understanding types based on free descriptions of learning strategy in post-tests. Those that included references to understanding relevance and meaning, such as "create a concept map" and "summarize important places in notes" were defined as the understanding type and those without reference to understanding of the meaning such as "read a textbook" and "search the Internet" were defined as the non-understanding type.

\subsection{Ethical Consideration}

This study was approved by the Ethics Committee at Hirosaki University (No. 2014-085).

\section{Results}

Forty-nine of 55 students participated in both the pre- and post-tests. Six students did not participate in the post-test. We analyzed data from 46 (intervention, $\mathrm{n}=19$; non-intervention, $\mathrm{n}=27$ ) of 49 participants, because those with a self-learning duration of "0 hours" were excluded.

\subsection{Self-Study Duration and Strategies}

The mean amounts of time that the intervention and non-intervention groups spent studying by themselves were $4.5 \pm 2.8$ vs. $2.7 \pm 1.4$ hours, respectively (minimum and maximum, 0.3 and 12.5 hours). The results of $t$-tests showed that the intervention group spent significantly more time studying by themselves than the non-intervention-group $(p<0.01)$. The results of $\chi^{2}$ tests showed that $17(89.5 \%)$ and $2(10.5 \%)$ participants in the intervention group applied understanding and non-understanding types of self-learning strategies, respectively, 
Table 2. Checklist to evaluate assessment skills.

\begin{tabular}{|c|c|}
\hline Symptom & High HbAlc. \\
\hline Data/Behavior & $\begin{array}{l}\text { Fasting blood glucose. } \\
\text { High blood pressure. } \\
\text { Height, } 173.3 \mathrm{~cm} \text {; Weight, } 80.4 \mathrm{~kg} \text {. } \\
\text { BMI, } 26.6 \mathrm{~kg} / \mathrm{m}^{2} \text {; obese. }\end{array}$ \\
\hline $\begin{array}{l}\text { Health management, } \\
\text { Current therapy/behavior/ } \\
\text { knowledge }\end{array}$ & $\begin{array}{l}\text { Complied with diet therapy for about } 2 \text { months after discharge, but } \\
\text { soon reverted to original lifestyle/habits. } \\
\text { Reference to how busy he is at work. } \\
\text { Self-checks blood sugar before breakfast. Injects insulin four times } \\
\text { daily. } \\
\text { Smokes } 10 \text { cigarettes/day. } \\
\text { Consumes up to } 600 \mathrm{~mL} \text { alcohol are bad for diabetes. } \\
\text { He believes that it is very difficult to quit; he needs them to work. } \\
\text { Can he understand the importance of compliance? } \\
\text { Consumes cafeteria lunch with meat and deep-fried foods. } \\
\text { Consumes sweet snacks before going home at night. } \\
\text { Supper is usually after } 10 \mathrm{pm} \text {. } \\
\text { Average dietary intake is } \sim 2500 \mathrm{kcal} / \text { day. }\end{array}$ \\
\hline $\begin{array}{l}\text { Diet therapy/ } \\
\text { Behavior/Strength }\end{array}$ & $\begin{array}{l}\text { Calorie intake } 500 \text { kcal over the recommended value. } \\
\text { His wife manages his diet at home. } \\
\text { He does not care about diet too much. } \\
\text { How to spend leisure time? } \\
\text { Describes difficulties living with therapy for diabetes. } \\
\text { Ineffective management of diet therapy. } \\
\text { Finds continuing diet therapy difficult. }\end{array}$ \\
\hline Lifestyle & $\begin{array}{l}\text { He can manage insulin therapy and blood glucose levels } \\
\text { Exercise habits. }\end{array}$ \\
\hline $\begin{array}{c}\text { Complications, Risk, } \\
\text { Observations }\end{array}$ & $\begin{array}{l}\text { Nephropathy and hypertension: Increased risk } \\
\text { Renal function } \\
\text { Retinosis } \\
\text { Blurred vision } \\
\text { Neuropathy } \\
\text { Numbness } \\
\text { Foot sores } \\
\text { Swollen gums } \\
\text { Gingivitis } \\
\text { Risk for complications: Neuropathy, retinosis, nephropathy } \\
\text { Chronic hypertension }\end{array}$ \\
\hline
\end{tabular}

Categories as below. Information described in case description; Care information. Highly relevant information not described in case description. Nursing problems and factors.

whereas only $5(18.5 \%)$ in the non-intervention group applied understanding-type strategies $(p<0.001)$. In the intervention group $15(79.0 \%)$ students described concept maps, whereas no one in the non-intervention group described concept maps.

\subsection{Structural Knowledge}

The results of analysis of variance in mean structural knowledge scores found no pre-test differences between the intervention and non-intervention groups, but 
the intervention group scored significantly higher in the post-test $(p<0.001)$ (Figure 1).

\subsection{Assessment Skill Evaluation}

We evaluated assessment skills using the checklist, calculated average scores for each assessment category, then compared the mean pre- and post-test scores (Figure 2).

The results of the analysis of variance of the intervention/non-intervention $\times$ pre-test/post-test $x$ assessment category revealed that these three categories tended to interact. Multiple comparisons using the Ryan method identified significant differences between intervention/non-intervention and pre/post regarding "nursing problems and factors". Post-test scores for the intervention group were significantly higher than those in pre-tests $(p<0.001)$ and also significantly higher than post-test scores of the non-intervention group $(p<0.01)$.

On the other hand, pre- and post-test scores for assessing nursing problems and factors in the non-intervention group did not significantly differ (Figure 2). Pre-test scores for "patient information" were significantly higher for the non-intervention group $(p<0.05)$, but post-test scores did not significantly differ (Figure 2).

\section{Discussion}

\subsection{Changes in Structured Knowledge before and after the Education}

Understanding associations regarding diabetes appeared to increase in the intervention group based on the finding that structured knowledge increased only in this group in the post-test. Our educational intervention seemed to have influenced strategies to self-study diabetes, although the students had not yet finished learning about diabetes. We considered that learning medical knowledge in relation to a clinical scene encouraged structural knowledge, with explicit

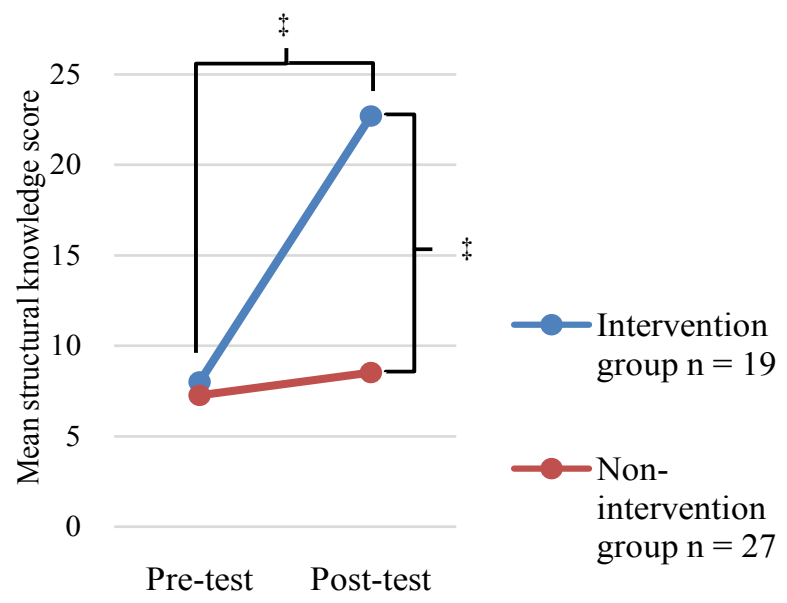

Figure 1. Pre- and post-test scores for concept map drawing task. ${ }^{\ddagger}=p<0.001$; analysis of variance. 


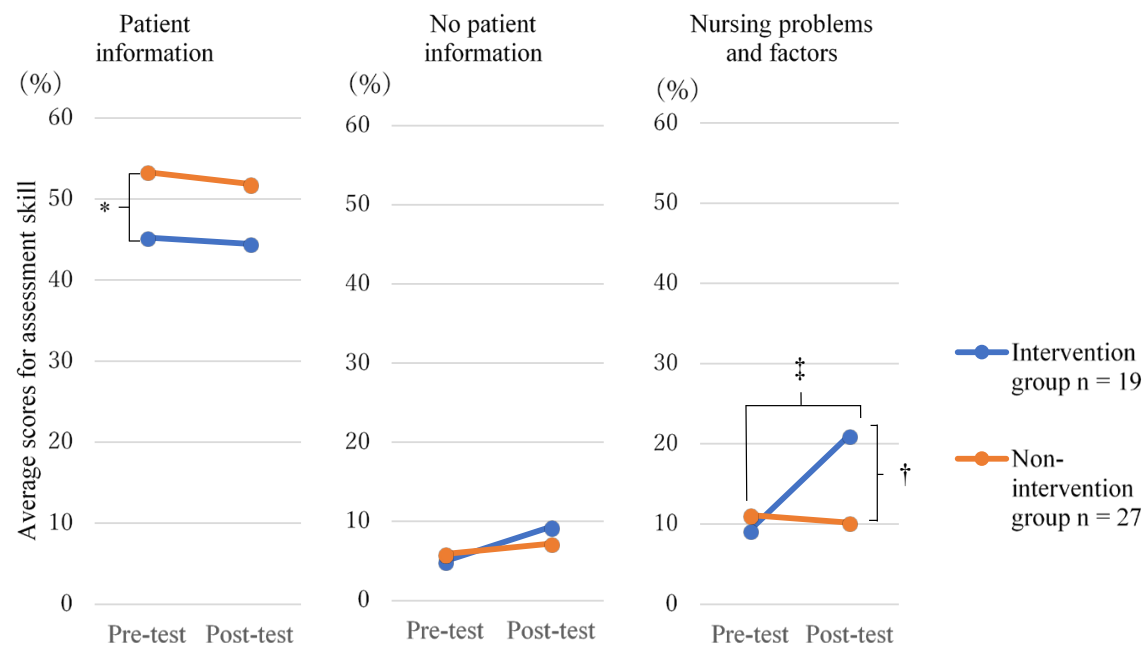

Figure 2. Assessment skill scores for each category. ${ }^{\star} p<0.05,{ }^{\dagger} p<0.01,{ }^{\ddagger} p<0.001$; analysis of variance.

conditions for applicability. Appropriate application of knowledge enabled the students to effectively assess patients. Also, such thinking takes place in working memory. Advanced skills are required to simultaneously process multiple pieces of new information, although the processing capacity of working memory varies among individuals. To process large amounts of information, problem-solving using diagrams reduces the amount of thinking effort required [15]. Ito T., et al. [16] indicated that one validity of a diagram in the thinking process of problem-solving is "Entirety". That is, entire relationships among pieces of information are easier to grasp from a diagram. Furthermore, creating a diagram has more effect on thinking than simply thinking using an already prepared diagram because describing self-made diagrams not only promotes thinking by externally maintaining thought processes, but also renders the thinking process more objective, which in turn promotes further thinking [17]. Learning strategies described by a student based on self-made diagrams indicates that understanding the relationships among pieces of knowledge augments understanding of their relevance from the viewpoint of entirety.

This learning strategy has the feature of meaningful learning. Facts gained from rote learning may lack cohesiveness. However, putting information together in meaningful ways improves information retention and understanding [8]. The intervention group seemed to have learned the effect of meaningful learning during the educational intervention using meaningful learning strategies. The self-learning strategies for diabetes applied by the non-intervention group focused on gaining information by means such as "reading a textbook" or "searching the Internet". However, the intervention group focused on understanding important information derived from data in concept maps that they created or summarizing important information in notes as well as connecting information with the actual status of the clinical patients. Therefore, knowledge of diabetes was considered to be structured because the relationships between pieces of information were understood. 


\subsection{Characteristics of Assessment Skills in Intervention and Non-Intervention Groups}

Regulating and integrating a regimen into one's daily life is important for chronic disease patients [18]. The presented patient could not self-manage a therapeutic dietary regimen because of low concern, whereas he self-managed a therapeutic medication regimen relatively well. Therefore, comprehensively considering the problem by seeing self-management ability and attitude regarding treatment not only from the aspect of dietary, but also medication therapy is important for this patient. The ability to identify the status of the patient and to identify nursing problems was significantly higher in the intervention group in the post-test, indicating that the educational intervention influenced the ability of the students to identify nursing problems. Participants in the intervention group apparently had better comprehension of the overall status of the patient by describing a concept map with the feature of Entirety. Therefore, the intervention group comprehensively identified the patient's status not only from the aspect of inadequate diet therapy self-management, but also from the aspect of well-managed medication therapy. On the other hand, the non-intervention group seemed unable to identify a relationship between self-managed diet and medication therapy because their comprehension of the overall status of the patient was insufficient, even though they could determine that self-management of diet therapy was insufficient.

With respect to the ability to collect information, which is the first step in an assessment, both groups could identify cue information from the statements presented by the patient. Students were randomly assigned to either group, but patient information scores for the intervention group were significantly lower than those in the non-intervention group at pre-test. However, since there was no significant difference between the intervention and non-intervention groups at post-test, it seems that the intervention also affected how information was collected.

However, the ability to recall information that was not described and applied was low.

Benner, P. [19] described a five-step process of skill acquisition. Beginners have had no experience of the situations in which they are expected to perform. They are taught about situations in terms of objective attributes and measurable parameters of a patient's condition that can be recognized without situational experience. At that point, the rule-governed behavior typical of a novice is extremely limited and inflexible. Second-year students before a clinical practicum seemed to have difficulty in recalling knowledge related to the situation and refer to existing knowledge and seemed to have difficulties with applying it to collect information. In actual nursing situations, students need to select and collect information to evaluate the health of a specific patient from vast amounts of patient-related data. Therefore, the ability to recall and apply the information needed to assess patient health status is required. 
Further studies are needed to determine educational methods related to the development of skills for collecting knowledge-based information.

The present findings indicated that educational intervention could improve the ability to identify nursing problems using structured knowledge with explicit conditions for applicability, although we did not teach the assessment strategies. Structured knowledge with explicit conditions for applicability and learning a way to apply such knowledge to assess a patient before a clinical practicum seemed to promote the effective development of the nursing process.

Therefore, this educational method might help to augment assessment skills.

Further studies are needed regarding educational methods related to developing assessment skills. Questions that might be addressed include how to educate students about thinking strategies to identify nursing problems and about how to apply knowledge to information collection.

\section{Conclusions}

The level of structured knowledge was significantly higher after an educational intervention compared with the absence of an intervention.

The ability to identify nursing problems was significantly higher after an educational intervention compared with the absence of an intervention.

These findings showed that studying new information while understanding relationships between extant knowledge and a clinical scene facilitates the development of assessment skills among nursing students.

\section{Acknowledgements}

This study was supported by JSPS KAKENHI Grant Numbers JP25862099 and JP16K11938. The authors are grateful for the invaluable information provided by the study participants.

\section{Conflicts of Interest}

The authors declare no conflicts of interest regarding the publication of this paper.

\section{References}

[1] American Nurses' Association (2018) The Nursing Process. https://www.nursingworld.org/practice-policy/workforce/what-is-nursing/the-nursi $\underline{\text { ng-process/ }}$

[2] Gordon, M. (2008) Assess Notes: Nursing Assessment \& Diagnostic Reasoning. FA Davis Company, Philadelphia.

[3] Ministry of Health, Labour and Welfare (2011) Report of Meeting on the Content and Method of Nursing Education. http://www.mhlw.go.jp/stf/houdou/2r9852000001310q-att/2r9852000001314m.pdf

[4] Hemming, T.R. and Jennrich, J.A. (2013) Using Standardized Patients to Strengthen Nurse Practitioner Competency in the Clinical Setting. Nursing Education Perspectives, 34, 118-121. 
[5] Sanmi, S., Yoshida, K., Yamamoto, K. and Kawanishi, M. (2016) Learning of OSCE That Second Year Nursing Students Have Realized in the Practical Clinical Training through the OSCE before the Fundamental Nursing Training. Bulletin of the Japanese Red Cross Hiroshima College of Nursing, 16, 89-97.

[6] Yula, H. and Walsh, M.B. (1983) The Nursing Process-Assessing, Planning, Implementing, Evaluating. Prentice-Hall Inc., Connecticut.

[7] Aoki, H. (2012) Effect of Utilizing Nursing Process Chart in Nursing Process Practical Training. Bulletin of the Graduate School of Education, Hiroshima University, 1, 199-204.

[8] All, A.C., Huycke, L.I. and Fisher, M.J. (2003) Instructional Tools for Nursing Education: Concept Maps. Nursing Education Perspectives, 24, 311-317.

[9] Collins, A.M. and Loftus, E.F. (1975) A Spreading-Activation Theory of Semantic Processing. Psychological Review, 82, 407-428. https://doi.org/10.1037/0033-295X.82.6.407

[10] Chi, M.T., Feltovich, P.J. and Glaser, R. (1981) Categorization and Representation of Physics Problems by Experts and Novices. Cognitive Science, 5, 121-152. https://doi.org/10.1207/s15516709cog0502_2

[11] Baddeley, A.D. (1990) Human Memory: Theory and Practice. Allyn and Bacon, Massachusetts.

[12] Baddeley, A.D. (2002) The Psychology of Memory. In: Baddeley, A.D., Kopelman, M.D. and Wilson, B.A., Eds., The Handbook of Memory Disorders, 2nd Edition, John Wiley \& Sons, Ltd., England, 3-15.

[13] Ichikawa, S. (1989) Introduction and Perspective of Cognitive Counseling. Japanese Psychological Review, 32, 421-437.

[14] Honda, I. (2014) Nursing for Patients with Diabetes. In: Onishi, K., Ed., Jirei de Manabu Kango Katei 2, Gakken Medical Shujunsha Co., Ltd., Tokyo, 60-69.

[15] Cheng, P.C.H. (2002) Electrifying Diagrams for Learning: Principles for Complex Representational Systems. Cognitive Science, 26, 685-736. https://doi.org/10.1207/s15516709cog2606_1

[16] Ito, T., Ohnishi, N. and Sugie, N. (1994) Problem Solving SCRIPT and Classification of Drawings for Explaining Human Drawing Processes. J77-D-2, The Institute of Electronic, Information and Communication Engineers Transactions, 811-822.

[17] Uesaka, Y. (2009) How Learning Skills Support through Cognitive Counseling Can Provide New Perspectives in Both Cognitive Research and School Curriculum Development: Focusing on the Strategy of Diagram Use in Problem Solving. Cognitive Studies, 16, 313-332.

[18] Herdman, T.H. (2012) NANDA International: Diagnoses: Definitions \& Classification, 2012-2014. Wiley-Blackwell, Oxford.

[19] Benner, P. (1984) From Novice to Expert. Addition-Wesley Publishing, Menlo Park. 